\title{
Diversidad e interculturalidad: La escuela indígena en contextos de migración
}

\section{Diversity and interculturality: The indigenous school in the context of migration}

\author{
Laura Velasco Ortiz a* (1) https://orcid.org/0000-0001-5754-6395
}

Daniela Rentería ${ }^{\text {b }}$ (D) https://orcid.org/0000-0002-7423-0285

\begin{abstract}
${ }^{a}$ El Colegio de la Frontera Norte, Departamento de Estudios Culturales, Tijuana, Baja California, México, correo electrónico: lvelasco@colef.mx

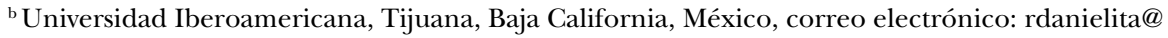
gmail.com
\end{abstract}

\section{Resumen}

El objetivo del artículo es describir y analizar la diversidad cultural en escuelas indígenas y los retos de la interculturalidad frente a la discriminación étnico-racial. Metodológicamente, el artículo se basa en una encuesta sobre diversidad cultural a una muestra de 14 escuelas y en 21 grupos focales, con alumnado

Recibido el 3 de octubre de 2018 Aceptado el 8 de enero de 2019. Publicado el 24 de enero de 2019.

${ }^{*}$ Autor para correspondencia: Laura Velasco Ortiz, correo electrónico: Ivelasco@colef.mx

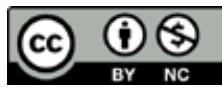

Esta obra está protegida bajo una Licencia Creative Commons Atribución-NoComercial 4.0 Internacional. y docentes de las 70 escuelas del sistema de educación indígena en Baja California. Los hallazgos señalan una diversidad cultural escolar alimentada por los mismos elementos que surgen como objetos de discriminación étnico-racial y migrante como base de la construcción inferiorizada de la categoría indígena -migrante y nativo-, en torno a la práctica de alguna lengua indígena, el color de la piel y su ancestralidad. Algunas limitaciones del artículo provienen de su atención a la población del alumnado y aunque considera la interacción docente, no analiza la diversidad de ese actor en el espacio escolar.

Palabras clave: diversidad cultural, interculturalidad, espacio escolar, discriminación étnico-racial e inferiorización simbólica.

\section{Abstract}

The objective of the article is to describe and analyze cultural diversity in indigenous schools and the challenges of interculturality in the face of ethnic-racial discrimination. Methodologically, the article is based on a survey on cultural diversity to a sample of 14 schools and in 21 focus groups, with students and teachers of the 70 schools of the indigenous education system in Baja California. The findings point to a school cultural diversity fed by the same elements that emerge as objects of ethnic-racial and migrant discrimination as the basis of the inferiorized construction of the indigenous -mi-

CÓMO CITAR: Velasco, L. y Rentería, D. (2018). Diversidad e interculturalidad: La escuela indígena en contextos de migración [Diversity and interculturality: The indigenous school in the context of migration]. Estudios Fronterizos, 20, e022. doi:https://doi. org/10.21670/ref.1901022 
grant and native category-, around the practice of some indigenous language, the skin color, and ancestrality origin. Some limitations of the article come from its attention to the population of the students and although it considers the teaching interaction, it does not analyze the diversity of that actor in the school space.

Keywords: cultural diversity, interculturality, school space, ethnic-racial discrimination, symbolic inferiorization.

\section{Introducción}

Desde los años ochenta existe una crítica a las políticas indigenistas del Estado mexicano, nutrida en gran medida por los propios pueblos indígenas. Una de las dimensiones más criticadas es la educación intercultural bilingüe como medio de integración de los pueblos indígenas. Después de décadas de la existencia del paradigma de la interculturalidad en el sistema de educación indígena como parte del programa nacionalista, surgen algunos retos que provienen, entre otras fuentes, de la configuración de la diversidad cultural de México, bajo los grandes flujos migratorios internos e internacionales. Así, la educación intercultural enfrenta, en la práctica, una complejidad de diversidades etnoculturales que proviene de las migraciones multiétnicas y de la existencia de pueblos indígenas de matrices culturales distintas.

El objetivo de este ensayo es reflexionar sobre la diversidad cultural que caracteriza a las escuelas de educación indígena en Baja California, un estado del norte de México que ha sido fundado por migraciones multiétnicas de todo el país y a la vez que posee presencia de pueblos indígenas de matriz aridoamericana. En particular interesa comprender cómo tal diversidad reta la interculturalidad en las escuelas indígenas en el estado, frente a las dinámicas de la discriminación étnica y racial entre el alumnado. La reflexión surge de un interés inicial de orden pragmático de entender cómo enfrentan los docentes de escuelas del sistema de educación indígena la diversidad cultural del alumnado en contextos urbanos y semiurbanos caracterizados por procesos de migración y asentamiento en el estado de Baja California. ${ }^{1}$

El presente artículo es un primer paso en el análisis de los resultados de la investigación que se sitúa en el campo de la relación entre la escuela, como espacio de encuentro cultural, y otros procesos de construcción de la diferencia cultural, como el racismo y la discriminación étnica. El interés hace eco de los esfuerzos institucionales, de las organizaciones indígenas y de la sociedad civil por generar conocimiento orientador de políticas educativas con sentido intercultural, teniendo como referencia la condición indígena en yuxtaposición con la de migrantes de los alumnos y personal docente. También se inscribe en un horizonte intelectual amplio que indaga sobre el papel de la escuela en la transformación de la cultura en sociedades con alta movilidad geográfica y diferenciación étnica; el debilitamiento de la cultura como referente de unión (Wieviorka, 2003, p. 26), y su fortalecimiento como fuente de división y

\footnotetext{
${ }^{1}$ El proyecto de investigación del que surge este artículo es Diagnóstico y evaluación de las estrategias escolares para la interculturalidad: Experiencias locales ante la diversidad cultural de Baja California, financiado por el Fondo Sectorial de Investigación para la Educación SEP-Conacyt, Proyecto 1282 (20142015).
} 
fragmentación, exige atención institucional y de los académicos. En la idea de que la escuela es un espacio donde se puede incidir en lograr un encuentro y comunión entre individuos culturalmente diferentes.

\section{Discusión conceptual}

En México, la polémica sobre la educación indígena está en el origen del proyecto indigenista en el marco del nacionalismo mexicano (Bonfil, 1989; Díaz-Polanco, 1978). Según Guillermo de la Peña el término indigenismo fue acuñado para "referir al conjunto de discursos, categorizaciones, reglas, estrategias y acciones oficiales que tienen el propósito expreso de crear un dominio de Estado sobre los grupos designados como indígenas" (Peña, 2005, p. 719). Desde muy temprano en el proyecto nacionalista, en la escuela rural convergieron acciones específicas educativas e indigenistas (Stavenhagen, 2006).

El indigenismo ha evolucionado por distintos modelos acordes a los cambios del propio Estado nación mexicano y de las movilizaciones indígenas en el continente latinoamericano. El indigenismo crítico de los años ochenta permitió dejar atrás el discurso asimilacionista y transitar a lo que se puede denominar como indigenismo participativo (Barabas, 2000; Peña, 2005) y de transferencia hacia los colectivos indígenas.

En 1992 a raíz del convenio 169 de la Organización Internacional del Trabajo (оIT) se realiza una reforma constitucional que reconoce el carácter multiétnico y pluricultural del país, en la misma línea de la Declaración de Barbados y la reivindicación del derecho de los pueblos indígenas a impulsar un etnodesarrollo, con la valoración de las lenguas y costumbres, entre otros elementos. Este razonamiento intenta establecer el carácter de derecho que toma la interculturalidad en relación a los pueblos indígenas en México y su realización en diferentes políticas, entre ellas la educativa. Como lo señala Schmelkes (2004), para dar cabal cumplimiento al postulado constitucional de la composición pluricultural de México, es necesario un programa participativo de educación intercultural y de investigación que permita desarrollar conocimiento y estrategias informadas al respecto. ${ }^{2}$

El desafío que nos propone el paradigma de la educación intercultural no se ciñe solo al bilingüismo de lenguas indígenas y del español, sino a la comunicación y convivencia de formas culturales distintas (Grimson, 2011) en el espacio escolar y su proyección hacia otros espacios sociales. Si bien un eje central de la educación intercultural en México es la participación de los pueblos indígenas, el reto de enseñanza y convivencia en el espacio escolar involucra a las demás categorías étnicas y regionales a las que se adscriben directivos, maestros y alumnos (Corona y Barriga, 2004), ya que el acto comunicativo implicado en la interculturalidad involucra a poblaciones indígenas y no indígenas.

Un primer acercamiento señala un campo de conocimiento fragmentado con aportes de las propias instituciones educativas como la Universidad Pedagógica Nacional, de instancias organizativas como el Congreso Nacional de Educación Indígena e Intercultural y el Consejo Mexicano de Investigación Educativa (COMIE),

\footnotetext{
${ }^{2}$ En 1992, México se reconoce constitucionalmente como un país pluricultural, sustentado originalmente en los pueblos indígenas (Ramírez y Lara, 2009).
} 
algunos centros de investigación con especialistas de disciplinas distintas como la Sociología y la Antropología y por supuesto los propios profesionistas y directivos de la educación indígena e intercultural. No es extraño que el conjunto de actores involucrados e interesados en el desarrollo del modelo intercultural tenga expectativas y concepciones sumamente diferentes, a veces incompatibles y en contradicción (Muñoz, 2001, p. 310). Dietz, Mendoza y Téllez (2008) ven en la educación indígena un campo en lucha entre diferentes actores con intereses enfrentados. Un recordatorio oportuno de que esta política educativa tiene origen en la crítica antisistémica y anticolonial en los años noventa (Walsh, 2007), dada la desigualdad y la discriminación de los indígenas en el espacio escolar y que muy pronto fue absorbida por la política étnica del Estado.

Para la comprensión de la relación entre diversidad cultural e intercultural se proponen los siguientes dos ejes analíticos: por un lado, la relación entre educación y los modelos de diversidad cultural; y por el otro, la constitución de la escuela como espacio escolar diverso a raíz de las migraciones que alimentan los contextos regionales específicos.

\section{Multiculturalidad y educación intercultural}

Como lo apunta Medina (2007), la investigación sobre diversidad sociocultural e interculturalidad se ha posicionado como un campo de estudio que ha cobrado un lugar preponderante en las ciencias sociales y las humanidades, pero lo ha hecho desde conceptos diferentes y además polisémicos como multiculturalismo, diversidad cultural, interculturalidad por mencionar algunos. Esta situación nos obliga a hacer explícitos los significados que le otorgamos a los conceptos de multiculturalidad, interculturalidad y educación intercultural bilingüe en este trabajo.

La multiculturalidad es, de acuerdo con Schmelkes, "un concepto descriptivo que se refiere a la coexistencia de personas y/o grupos culturalmente diferentes en espacio o territorios determinados; no se refiere a la relación entre estas personas y grupos" (2004, p. 11) y generalmente tiene como referencia el Estado nación. Por su parte, la interculturalidad es un concepto dinámico, que hace referencia a las relaciones que se entablan entre diferentes sistemas culturales a partir del reconocimiento y respeto de la diferencia. De acuerdo con la Organización de las Naciones Unidas para la Educación, la Ciencia y la Cultura (Unesco), la interculturalidad se define como:

La presencia e interacción equitativa de diversas culturas y la posibilidad de generar expresiones culturales compartidas, adquiridas por medio del diálogo y de una actitud de respeto mutuo. La interculturalidad supone el multiculturalismo y es la resultante del intercambio y el diálogo «intercultural en los planos local, nacional, regional o internacional (Unesco, 2006, p. 17).

La idea de que la interculturalidad puede ser una posibilidad de superar relaciones asimétricas de poder entre culturas con nuevas relaciones basadas en la igualdad y el respeto (Sandoval, 2004, p. 57); puede resultar una práctica complicada pero funcionar adecuadamente como valor orientador de las acciones institucionales.

El enfoque de la educación intercultural propone "incorporar las diferencias y [...] la igualdad de oportunidades por medio del respeto y tolerancia a la diversidad y pluralidad cultural, reconocer y valorar la diferencia en la búsqueda de puntos de 
encuentro" (Cedillo et al., 2002, p. 3). Cabe acotar que como señala Schmelkes (2004), el modelo de la educación intercultural no es fijo sino por el contrario considera las características del contexto social, así como la heterogeneidad cultural y las fronteras múltiples al interior de las categorías étnicas y culturales que entran en contacto e interacción en el espacio escolar. Además, la interculturalidad no solo entraña un encuentro armonioso sino conflictivo asociado a las relaciones de poder que atraviesan el espacio escolar.

En México, la institucionalización de la educación intercultural inició desde los años noventa del siglo xx y encuentra su cúspide en la creación de la Coordinación General de Educación Intercultural y Bilingüe (CGEIB), la cual busca a través de:

Un conjunto de procesos pedagógicos intencionados, la formación de personas capaces de comprender la realidad desde diversas ópticas culturales y de intervenir en procesos de transformación social que respeten y se beneficien de la diversidad cultural. Esto supone tanto el conocimiento profundo de la lógica cultural propia, como el de lógicas culturales diferentes (CGEIB, 2004, p. 49).

$\mathrm{Al}$ respecto, los estudios dentro de la línea de investigación "enseñanzas y aprendizajes socioculturales y su articulación curricular" del Consejo Mexicano de Investigación Educativa (COMIE), concentran un acervo de conocimiento donde se analizan experiencias relacionadas con la articulación entre los saberes o las prácticas socioculturales de la comunidad y los contenidos escolares convencionales, pues para los autores, la creación de una cultura escolar asociada a la interculturalidad, solo es posible a través de la vinculación entre los distintos actores educativos (Bertely, 2006; Bertely, Gasché y Podestá, 2008).

La investigación que da base empírica a este artículo indaga sobre el efecto de la política intercultural en la vida cotidiana de las escuelas, más allá del currículo escolar, creando proyectos diversos de promoción de la convivencia intercultural, que no solo implica la diferencia étnica sino otro tipo de diferencias culturales como son las asociadas a los orígenes locales, regionales y nacionales de la población escolar, resultado de la migración y movilidad geográfica de los niños y sus familias.

\section{Educación intercultural, diversidad cultural y migraciones}

La multiculturalidad, antes definida, implica diversidad cultural en un territorio específico. Aquí se agrega la importancia de considerar la historicidad de las configuraciones étnicas a nivel nacional y regional para comprender tal diversidad cultural, así como el proyecto de educación intercultural como una política cultural del Estado, con arraigo en las movilizaciones indígenas en América Latina (Dietz y Mateos, 2013). En una primera mirada, se podría asumir que la configuración cultural de sociedades excoloniales como las latinoamericanas difieren de aquellas constituidas por flujos de migrantes como es el caso de Estados Unidos y Canadá, sin embargo en el curso de la historia vemos casos — como el de México-donde estas dos configuraciones parecen encontrarse como resultado de las migraciones mexicanas y los flujos de retorno desde Estados Unidos. La configuración étnico-racial (indígenas, mestizos y afrodescendientes), de herencia colonial española, perfila una diferenciación cultural 
entre los indígenas y mestizos con relaciones de subordinación y discriminación añejas, la masividad de las migraciones de las poblaciones indígenas han forjado nuevas líneas de diferenciación cultural. Los contactos culturales producidos por las migraciones internas e internacionales en los espacios escolares han alterado las delimitaciones rígidas de los modelos culturales, al poner en contacto a niños de orígenes locales, regionales, nacionales y étnicos diversos. De tal forma que la escuela se convierte en un mosaico sumamente complejo de adscripciones e identificaciones que remodelan las líneas de poder y discriminación con las que crecieron sus ancestros. Esto es muy visible en las ciudades y en regiones agroexportadoras mexicanas donde se observan poblaciones de origen indígena de varias generaciones conviviendo en espacios locales con poblaciones de diversos orígenes étnicos, raciales y regionales.

Ahora bien, la complejidad migratoria no oscurece la diferenciación étnica colonial y el prejuicio hacia los indígenas (Schmelkes, 2004). Por ello es que la multiculturalidad pasa necesariamente por la condición plurilingüe del país, con 62 grupos etnolingüísticos de origen prehispánico, presentando un importante desafío para la implementación del modelo de educación intercultural. Por ejemplo, a pesar de que existen materiales educativos en 56 lenguas indígenas y se distribuyen cerca de 2.5 millones de libros en lenguas indígenas (Hamel citado en López-Bonilla y Tinajero, 2011, p. 6). Las investigaciones sobre los procesos educativos en las escuelas indígenas (Czarny, 2008; Durin, 2007; Saldívar, 2006) revelan que, estas escuelas no trabajan la instrucción básica en lengua indígena porque los niños llegan hablando español y solo con algunas nociones de la lengua de su comunidad; asimismo, los profesores que están frente a grupo no siempre son hablantes de lengua indígena, o bien, no hablan la misma lengua que los niños. De manera que, a pesar de los modelos impulsados y los materiales elaborados, en las escuelas llamadas indígenas "el bilingüismo es menos que existente” (Barriga-Villanueva citado en López-Bonilla y Tinajero, 2011, p. 6).

En sociedades con un alto componente migratorio, las dificultades de contar con escuelas estrictamente bilingües, español y una lengua indígena, descansan en una multiplicidad de factores, entre los que destaca la heterogeneidad lingüística y de adscripciones locales y regionales con distinciones tales como norteños o sureños, oaxaqueños o zacatecanos, $\mathrm{u}$ otras de orden local o interétnica entre las regiones indígenas.

El ideal de igualdad que sostiene la perspectiva intercultural encuentra sus dificultades en las estructuras opresivas y discriminatorias hacia las poblaciones indígenas y hacia los inmigrantes pobres y racializados en las sociedades locales y nacionales. Por ejemplo, a partir de un estudio sobre niños indígenas en escuelas primarias públicas de la ciudad de México, Saldívar (2006) sostiene que el racismo histórico no solo se manifiesta en la discriminación de ciertos grupos sino en la valoración de otros por su clase, su fisonomía o identidad étnica. Menciona que en entrevista con los profesores se describía a los niños otomíes diciendo que "eran buenos para las artesanías (por su condición indígena) y eran buenos para los números (por su condición de pobreza)" (Saldívar, 2006, p. 117). Es así como concluye que la escuela comete el error de juntar características de identidad cultural con aspectos sociales, es decir, abona a la discusión sobre los discursos esencialistas que relacionan elementos fenotípicos con elementos sociales y culturales.

En esta perspectiva la escuela es un espacio de convivencia y conflicto cultural, donde el personal docente y alumnos generan día a día estrategias que no necesariamente responden a una planeación institucional sino a una creatividad articulada en prácticas cotidianas que pueden reproducir la desigualdad o bien salvarla. 


\section{La diversidad cultural en las escuelas indígenas de Baja California}

En el modelo nacionalista mexicano, el peso de la diferenciación étnico-racial puede oscurecer otras líneas de diferenciación cultural, como aquella surgida de las migraciones, de la condición de clase, género y la etaria. De hecho, en la actualidad los flujos migratorios son una de las fuentes de diversidad cultural y discriminación más importantes en el mundo, por lo que observar su traslape con ejes de diferenciación como los heredados por la colonización española puede ser de gran relevancia en la política educativa mexicana y para las sociedades locales y regionales en el territorio mexicano. La migración introduce complejidad a la realidad educativa y obliga al sistema educativo a ajustarse a gran velocidad para funcionar en contextos de movilidad estudiantil y de incremento de la diversidad cultural, dada los orígenes regionales y étnicos de la población escolar (alumnos y profesorado).

El estado de Baja California posee un componente de diversidad cultural asociado a su adyacencia e intensa interacción social con el estado de California en Estados Unidos, a la presencia de los pobladores nativos de origen prehispánico y a la vez, a las corrientes de migrantes provenientes del sur de México. Entre esas corrientes sobresalen por su condición étnica, los indígenas mixtecos y purépechas, quienes se han asentado en diferentes municipios del estado. Pero, la presencia de indígenas en Baja California ${ }^{3}$ no solo es resultado de la migración. Desde hace siglos existen grupos indígenas nativos asentados tanto del lado mexicano como del lado estadounidense de la frontera (Garduño, 2003). Desde mediados del siglo xx la población indígena se ha incrementado notoriamente por la inmigración procedente del sur de México; un flujo migratorio de tal grado, que en el año 2000 los indígenas de origen migrante constituían $99.8 \%$ de la población indígena del estado y los nativos constituían un porcentaje muy pequeño, aunque no por ello cualitativamente importantes (Corona y Serrano, 2010).

En 1982, la presencia de los indígenas inmigrantes en Baja California dio pie al traslado de profesores del sistema de educación indígena de Oaxaca, quienes se unieron a los profesores indígenas nativos, para ampliar el sistema educativo del estado. A tal grado que entre 1982 y 1999 el número de alumnos creció de 692 a 7 754, once veces, en tanto que los profesores aumentaron de 33 a 294, nueve veces (Lestage y Pérez, 2000). Este crecimiento del sistema educativo indígena no solo respondía a la inmigración constante, sino a la aparición de la segunda generación de indígenas de origen inmigrante; en el año 2000, 41.01\% de los integrantes de los hogares indígenas ya habían nacido en el estado de Baja California. Además dada la migración de distintas regiones de México, las escuelas indígenas bilingües recibían a niños no indígenas (Velasco, 2010).

En el año de 2010, a más de tres décadas de iniciado ese flujo migratorio indígena, las escuelas del sistema de educación indígena en Baja California suman 56 en total con una matrícula de 9453 alumnos, y una de sus características es que incluyen en sus aulas a niños de orígenes regionales y étnicos muy diversos, tanto nativos como inmigrantes, incluyendo a los niños que han nacido en el estado de California, del otro lado de la frontera. Es posible decir que en Baja California no existe un patrón

\footnotetext{
${ }^{3}$ Baja California es el tercer estado de la frontera norte con mayor población indígena (6\%), después de Sonora (10\%) y de Chihuahua (7.6\%) (Corona y Serrano, 2010, p. 34).
} 
de segregación étnica, con excepción de los campamentos de trabajadores agrícolas ${ }^{4}$ en el sur del estado, sino más bien un fenómeno de dispersión con algunos núcleos indígenas asentados con un patrón de origen local. Por ejemplo, en Tijuana las colonias con mayor presencia indígena son espacios pluriétnicos donde conviven personas oriundas de Oaxaca, Jalisco, Sinaloa o los nacidos en Baja California (Velasco, 2010). Esta diversidad es un componente importante de las escuelas de educación básica en general, acentuándose en las del sistema de educación indígena, por el enfoque de interculturalidad.

Así las escuelas indígenas se han vuelto un microcosmos de la diversidad cultural en Baja California, y en particular en ciudades tan cosmopolitas como Tijuana, donde $50 \%$ de la población nació en otro estado del país. Lo cierto es que aún con ese crecimiento, la población indígena en el estado registra niveles de escolaridad inferior a la no indígena. En el año 2000 los hogares indígenas reportaban un año de escolaridad inferior a los no indígenas (5.9 años de escolaridad, en tanto que los no indígenas tenía 6.94 años) (Corona y Serrano, 2010). Sin embargo, si vemos estos datos intergeneracionalmente se puede ver el efecto de la migración y el proceso de integración de los indígenas de segunda generación. Un estudio realizado en 2005 en la ciudad de Tijuana señaló un cambio generacional importante en la escolaridad de los hijos de los hogares indígenas (Coubès, Vela y Velasco, 2010). La distancia entre la escolaridad del jefe (3.6) y cónyuge (3.8) respecto de los hijos(as) (7.6) es de cerca de cuatro años; lo cual señala un proceso de integración escolar para la segunda generación, si consideramos que la media de escolaridad de los indígenas en Tijuana es de 6.29 años, la cual es muy cercana a la de los no indígenas (6.89 años). Quiere decir que para los jóvenes indígenas la escuela es una vía de integración social y cultural más importante que lo que fue para los padres, lo que hace más urgente saber sobre las estrategias escolares de integración cultural de la diversidad propia de estados con altas tasas de migración, como es Baja California.

Para acercarnos al universo de escuelas donde se concentra la población infantil de origen indígena y que a la vez registra el fenómeno de la migración, es pertinente considerar a las escuelas de la Dirección General de Educación Indígena (DGEI) y las escuelas inscritas en el Programa de Educación Básica para Niños y Niñas de Familias Jornaleras Agrícolas Migrantes (PRONIM), las cuales operan principalmente en los campamentos de los trabajadores agrícolas.

Vistas en conjunto, para el ciclo escolar 2011-2012, ambas modalidades de educación indígena y migrante atendían a 16446 alumnos a nivel básico (preescolar, primaria y secundaria) en las modalidades de educación indígena y migrante, representando $2.38 \%$ del alumnado total en el estado, distribuidos en 132 escuelas y atendidos por 614 docentes (Sistema Educativo Estatal [SEE], 2012).

El impacto de la migración indígena en la configuración cultural y escolar de Baja California tiene que distinguir los contextos urbanos de los contextos rurales. Ciudades como Tijuana, Mexicali y Ensenada presentan condiciones de vida notablemente distintas que las que dominan en las regiones agrícolas del estado. Un análisis de los hogares indígenas de Baja California en el año 2000 (Corona y Serrano, 2010)

\footnotetext{
${ }^{4}$ Estos campamentos en el Valle de San Quintín, municipio de Ensenada, han disminuido notablemente en la última década, y aún cuando se puede decir que son espacios de segregación indígena, a la vez poseen una diversidad étnica y regional, ya que conviven indígenas de diferentes matrices históricas y mestizos pobres de estados como Sinaloa y Sonora.
} 
encontró que la escolaridad media de los miembros del hogar indígena de cinco y más años de edad de Tijuana es prácticamente la misma que la de los hogares no indígenas (6.29 años), en tanto que los hogares indígenas del municipio de Ensenada, donde se concentra la mayor parte de los campamentos agrícolas, mostraron un rezago educativo respecto a los hogares no indígenas, de 3.4 años. Es interesante constatar, a través de un estudio realizado sobre las pautas de escolarización de los niños en la región agrícola del Valle de San Quintín, en el municipio de Ensenada, que el factor migratorio tiene mayor peso que la condición étnica en la asistencia escolar de los niños, es decir que los niños que nacieron fuera del municipio asisten menos a la escuela que los nativos, lo cual está probablemente relacionado con el trabajo infantil y la movilidad geográfica (Velasco y Coubès, 2006). De tal forma, que la condición migrante como trabajadores agrícolas funciona con mayor fuerza que la condición de indígena.

En este escenario, la noción de interculturalidad es distinta en cada uno del tipo de asentamiento rural o urbano. Como lo muestra Cedillo et al. (2002), las escuelas indígenas cercanas a los campos agrícolas poseen una diversidad étnica que se asocia a la residencia del campamento, donde los trabajadores y sus familias son acomodados por los camperos, y donde las redes de paisanaje funcionan, pero la convivencia con personas de otros pueblos o regiones es sumamente frecuente. A ello, se agrega el trabajo agrícola de los niños, ya sea en forma permanente o temporal. Esta situación afecta en su rendimiento académico y en el tiempo que tienen para poder dedicarlo a la escuela. El estudio de Cedillo et al. (2002) señala también la necesidad de un trabajo interinstitucional entre las instancias involucradas (Secretaría de Educación Pública [SEP], Programa Nacional con Jornaleros Agrícolas [PRONJAG], Instituto Nacional para la Educación de los Adultos [INEA], Desarrollo Integral para la Familia [DIF]) para poder generar un plan de educación intercultural bilingüe flexible que logre satisfacer las demandas de la población infantil migrante. La movilidad geográfica característica de las escuelas con poblaciones migrantes se agudiza en las zonas agrícolas, como lo describen Castro (2002) al estudiar los retos de los profesores de educación indígena en el estado de Sinaloa: inasistencia a la escuela, jornadas escolares más cortas y la dificultad de la continuidad de los niños en las aulas.

El fenómeno migratorio produce una multiculturalidad que logra su expresión plena a nivel regional o local y en espacios específicos de interacción o interrelación. Cada escuela es un universo de diversidad cultural que genera su propia dinámica intercultural y requiere a la vez estrategias específicas de gestión que no siempre esperan los tiempos de planeación o programación, sino que se producen en el camino de la actividad cotidiana institucional.

\section{La metodología del estudio}

La investigación tuvo como universo de estudio a las escuelas del sistema de educación indígena en Baja California por dos razones. Primero, debido a que partimos de la interrogante de ¿Cómo este subsistema de educación indígena enfrenta la diversidad cultural migratoria y étnica a través de las estrategias docentes en el aula? Y segundo, en estudios previos (Velasco, 2010; Velasco, Zlolniski y Coubès, 2014) documentamos la concentración espacial de la población indígena en ciertas colonias de los centros urbanos del estado y su correspondencia con las escuelas de educación indígena. 
Ambas razones fundaron la decisión de concentrarnos en el sistema de educación indígena. La metodología consideró dos etapas: la primera que consistió en el diseño y levantamiento de un censo escolar en una muestra de 14 escuelas primarias de educación indígena, y una segunda etapa que consistió en 21 grupos focales de profesores y alumnos en la muestra encuestada del mismo sistema de educación indígena en Baja California. ${ }^{5}$

En la primera etapa se levantó un cuestionario de forma censal en una muestra de 14 escuelas primarias dependientes de la DGEI, coordinación Baja California, a partir de los indicadores de diversidad: lugar de nacimiento, etnicidad y lengua indígena, para conocer las características sociodemográficas de los niños y los padres de familia.

A partir de la información del Sistema Nacional de Información de Escuelas (SNIESC) se definió un universo de 70 escuelas indígenas nivel primaria en el estado de Baja California.

El criterio para la selección de las 14 escuelas fue tener una diversidad de escuelas según: a) municipios y delegaciones, b) modalidades de atención (unitaria, multigrado o general) y c) escuelas con población migrante o nativo. El municipio de Ensenada concentra el mayor número de escuelas de educación indígena $(81.43 \%)$, le sigue Tijuana, Playas de Rosarito, Mexicali y finalmente Tecate. La muestra cuidó representar esta distribución a nivel municipal. ${ }^{6}$

Cada escuela de la muestra fue censada entre febrero y abril de 2014, obteniendo un total de 2711 cuestionarios, que representan $20.36 \%$ del total de la población que son 10660 niños y niñas.

En la segunda etapa de trabajo de campo se realizaron 21 grupos focales, 12 con el alumnado y 9 con docentes; en conjunto participaron 171 individuos. En el grupo focal con niños se solicitó la participación por escuela de al menos ocho alumnos. Los criterios de selección fueron: grado escolar, sexo y lengua indígena. En ese sentido, se buscó que participaran en igual proporción niñas y niños y que participaran niños hablantes y no hablantes de lengua indígena. En el caso del grupo focal con profesores también se buscó diversidad lingüística, grado escolar y sexo.

\section{La escuela diversa y los obstáculos a la interculturalidad}

En Baja California no existe un modelo de gobierno multicultural. El sistema de educación indígena que opera en el estado deriva de una política federal, acorde a la constitución mexicana, que reconoce la condición multicultural del país, heredera del nacionalismo del siglo xx. Esa condición multicultural está planteada en el contexto de la composición muticultural de raíz étnica ex-colonial del siglo xvi. En este modelo, a diferencia de otros países como Estados Unidos, la diferencia étnica se funda en la experiencia de conquista y colonia española, antes que en las corrientes migratorias. En Baja California existe la coincidencia a nivel regional y local de esas dos fuentes de diversidad: la diversidad étnica a partir de la colonización y la que proviene de los flujos migratorios internos e internacionales.

${ }^{5}$ Para mayor información ver Velasco y Rentería (2015).

${ }^{6}$ La muestra tuvo la siguiente distribución porcentual: Ensenada 57.14\%; Tijuana $21.43 \%$; Playas de Rosarito, Mexicali y Tecate $7.4 \%$, respectivamente (Velasco y Rentería, 2015). 
La propuesta de Verdery (1994) sobre la importancia del origen histórico-cultural es útil para comprender los procesos de diferenciación cultural en sociedades de alta migración. Verdery (1994) considera que la etnicidad en sociedades con altainmigración está caracterizada por el origen geográfico de los inmigrantes produciendo procesos complejos de reterritorialización simbólica. Las escuelas pueden ser pensadas como espacios donde confluyen una diversidad de orígenes geográficos y étnicos con esas territorialidades múltiples, a la vez diversos por la diferencia de edad, el género. Existen diferentes edades entre niños y niñas, algunos muy pequeños recién ingresados de 6 años y otros entrando a la adolescencia a sus 12 años en sus últimos años de primaria. Del total de alumnos encuestados, $51.5 \%$ son hombres y $48.5 \%$ son mujeres, cuyas edades se encuentran entre los 6 y los 12 años, con porcentajes más altos en las edades de 8,9 y 10 años, que en conjunto constituyen casi la mitad de la población escolar $(40.7 \%)$. En este punto, nos concentramos en dos fuentes de diversidad que producen una diferencia cultural clara en el espacio escolar, dejando de lado la etaria y la de género, no por ser menos importante, sino porque en este trabajo privilegiamos el análisis de lo étnico y regional, dada la caracterización indígena del sistema educativo aquí analizado. El concepto de origen histórico-cultural es una guía para analizar tal diversidad y construcción de la diferencia cultural. El concepto de origen históricocultural entraña ancestralidad, que implica conexiones generacionales, localización geográfica y prácticas culturales.

El origen geográfico, regional y nacional, entraña diferentes orígenes históricos de las familias a las que pertenecen los niños y niñas; por ejemplo en México nació 93.1\% , 3.8\% en Estados Unidos y solo se registró el caso de un niño que nació en Honduras. Del total de alumnos nacidos en México, la gran mayoría son nacidos en Baja California $(72.2 \%)$ y casi una tercera parte $(27.8 \%)$ nació principalmente en los estados de Oaxaca $(8.8 \%)$, Guerrero (2.5\%), Sinaloa (2.5\%) y Michoacán (1.8\%), lo cual señala un flujo reciente de migración. Los datos antes expuestos señalan una movilidad compleja que incluye trayectorias de desplazamientos familiares distintas que incluyen migración desde el sur de México, desplazamientos en la región del noroeste y retornos familiares desde Estados Unidos, bien porque encuentran un ambiente más bicultural que al interior del país. En el caso de los alumnos que nacieron en Estados Unidos se encontró que poco más de la mitad no sabe en qué estado nació. Sin embargo, los niños que sí lo saben indicaron los estados de California, Arizona, Florida, Oregón, Virginia y Washington.

La mayoría de los padres de familia de la población escolar han nacido en México: $97.8 \%$ de los padres y $98.5 \%$ de las madres. Son pocos los casos que registran haber nacido en otros países: Estados Unidos, Honduras, El Salvador, Guatemala y Filipinas.

En la Figura 1 se puede observar que en proporción similar, los padres y las madres que nacieron en México son originarios de los estados de Oaxaca, Baja California, Guerrero, Sinaloa, Michoacán y Veracruz, principalmente. El estado de Oaxaca es el origen de poco más de la tercera parte de los padres; segundo estado con mayor concentración de población hablante de lengua indígena a nivel nacional en 2010 (Instituto Nacional de Estadística y Geografía [Inegi], 2010). 
Figura 1. Estado de nacimiento en México de los padres de familia de alumnos de escuelas de educación indígena de primaria de Baja California (porcentajes)

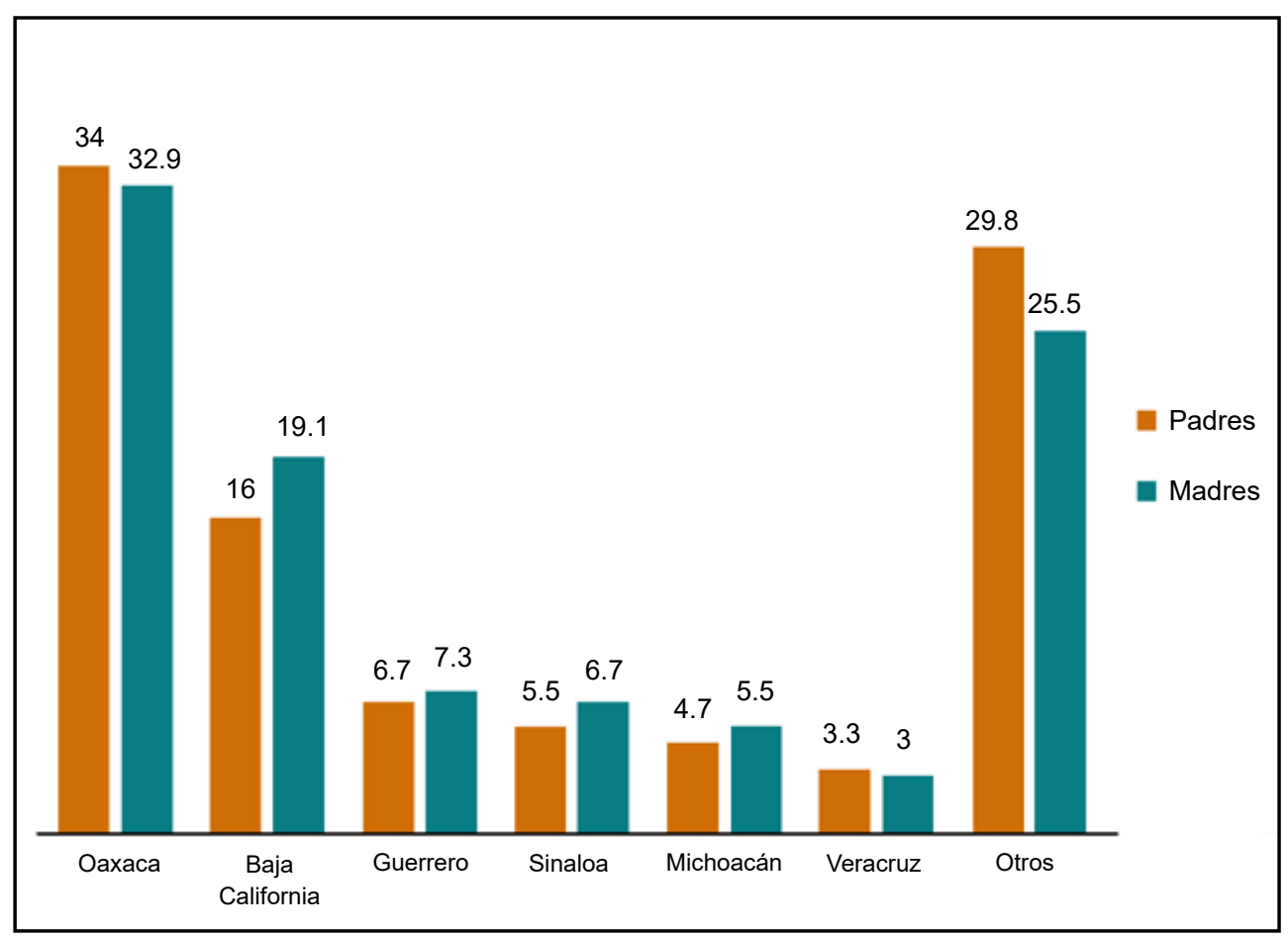

Fuente: Elaboración propia con la base de datos del Cuestionario a Niños, Diagnóstico y evaluación de las estrategias escolares para la interculturalidad: Experiencias locales ante la diversidad cultural de Baja California, El Colegio de la Frontera Norte, 2014.

La comparación entre los lugares de nacimiento de los padres y de los niños nos permite afirmar que hay un cambio generacional importante, ya que casi $80 \%$ de los padres son nacidos fuera de Baja California, en tanto que esa categoría disminuye a $27.8 \%$ entre los hijos que asisten a la escuela indígena. Las escuelas indígenas del estado son pobladas por niños y niñas nativas que constituyen en su mayoría la segunda generación de migrantes. Este hallazgo plantea el reto de conceptualizar el origen geográfico como lugar ancestral con el que se tiene una relación simbólica más que práctica, como lo es el caso de los padres.

\section{El origen lingüístico y la lengua materna}

El escenario de la diversidad lingüística en la población escolar muestra la vitalidad de lenguas indígenas, además del español (Figura 2). Al observar este dato en su asociación con el uso de la lengua indígena entre los padres resulta relevante señalar la disminución intergeneracional del uso de la lengua indígena entre los hijos e hijas. Esta información es consistente con los estudios realizados en Tijuana (Velasco, 2010) en hogares donde se ha encontrado una disminución intergeneracional del uso de la 
lengua indígena. No obstante, poco más de una tercera parte de los niños que asisten a las escuelas encuestadas habla alguna lengua indígena.

Figura 2. Comparación de habla de lengua indígena entre padres, madres y niños(as) de escuelas de educación indígena en Baja California (porcentajes)

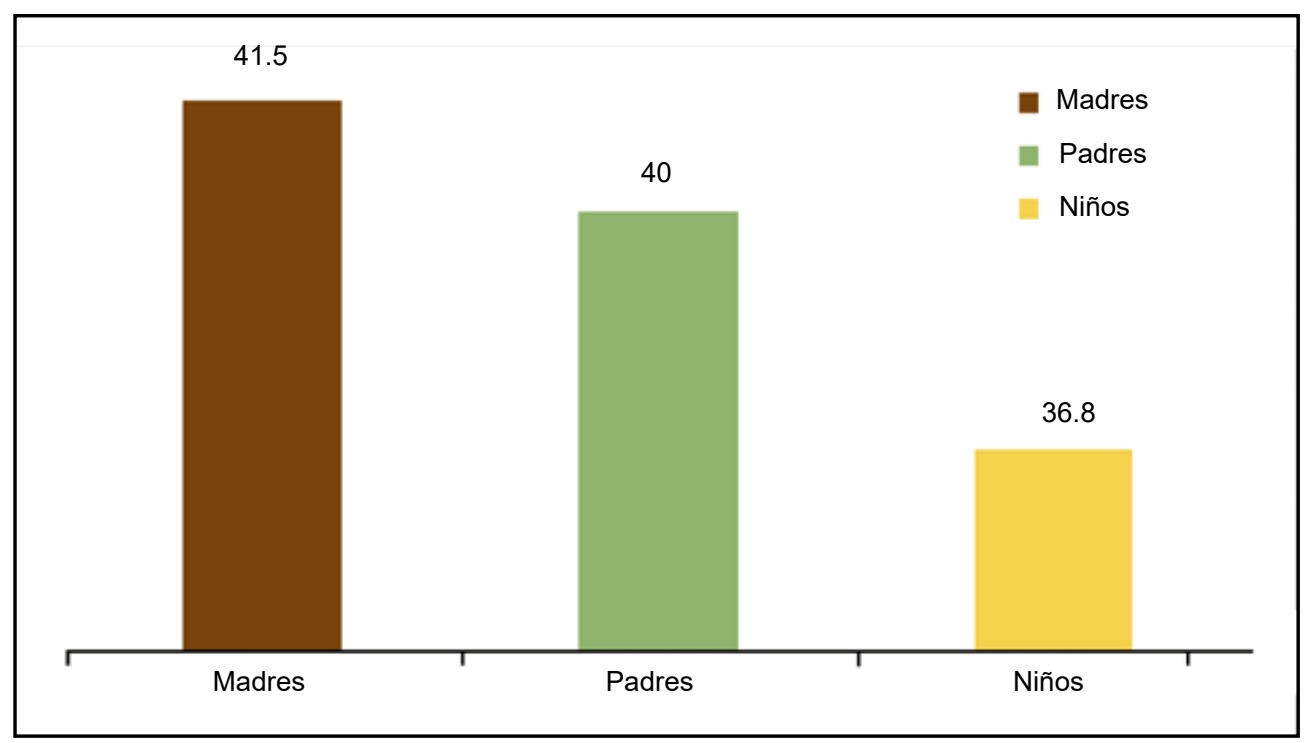

Fuente: Elaboración propia con la base de datos del Cuestionario a Niños, Diagnóstico y evaluación de las estrategias escolares para la interculturalidad: Experiencias locales ante la diversidad cultural de Baja California, El Colegio de la Frontera Norte, 2014.

Se encontró que los niños y las niñas que asisten a las escuelas encuestadas presentan casos de monolingüismo, bilingüismo y trilingüismo de español, lengua indígena e inglés. El grupo más amplio es el de niños y niñas que son monolingües del español $(54.6 \%)$, lo cual es relevante en el contexto del Modelo Educativo Intercultural Bilingüe, a partir del cual trabajan estas escuelas, porque encontramos que poco más de la mitad de los niños tienen como lengua materna el español y no una lengua indígena. De tal forma que el cuerpo docente tiene que generar estrategias de adaptación de tal modelo a la situación escolar. En los grupos focales de profesores hubo coincidencia de que la lengua materna de la población escolar es el español. Por ejemplo, la profesora Catalina de la Escuela Sentimiento Purépecha en Rosarito dice, al entrar al salón como profesora: "es ahí cuando te das cuenta que los niños no hablan la lengua indígena y los padres tampoco. Fue un proceso de adaptación de mi parte, porque no había una guía (Soto, 2014).

Ante tal situación, en entrevista, el profesor Gustavo Sánchez (2014) dice: "el objetivo no es que los niños hablen la lengua indígena cien por ciento, sino que valoren y aprendan lo poquito que puedan aprender. Es promover la convivencia intercultural". O en palabras de la profesora Rogelia Santiago (2014): "más que nada fomentar la lengua indígena, ya que por alguna razón se ha perdido, rescatar la lengua indígena”. 
El segundo grupo intermedio, en términos porcentuales, lo constituye el de los niño(as) bilingües, ya sea por la combinación del español con una lengua indígena $(33.8 \%)$ o en una proporción significativamente más baja con el inglés $(5.1 \%)$. El bilingüismo español-lengua indígena es resultado de una práctica familiar donde la lengua indígena es medio de comunicación, recreación y socialización de los niños(as). En el caso del bilingüismo español-inglés responde a la condición fronteriza de Baja California, en la que las familias pueden tener una vida cotidiana ligada a la práctica commuter, o redes familiares transfronterizas o bien porque nacieron o crecieron en Estados Unidos y sus padres han sido deportados desde ese país.

Un tercer grupo de trilingües, que aunque pequeño, es significativo culturalmente $(2.3 \%)$, son hablantes de español, inglés y alguna lengua indígena (ver Figura 3).

Figura 3. Diversidad lingüística de los niños(as) de escuelas indígenas nivel primaria en Baja California (porcentajes)

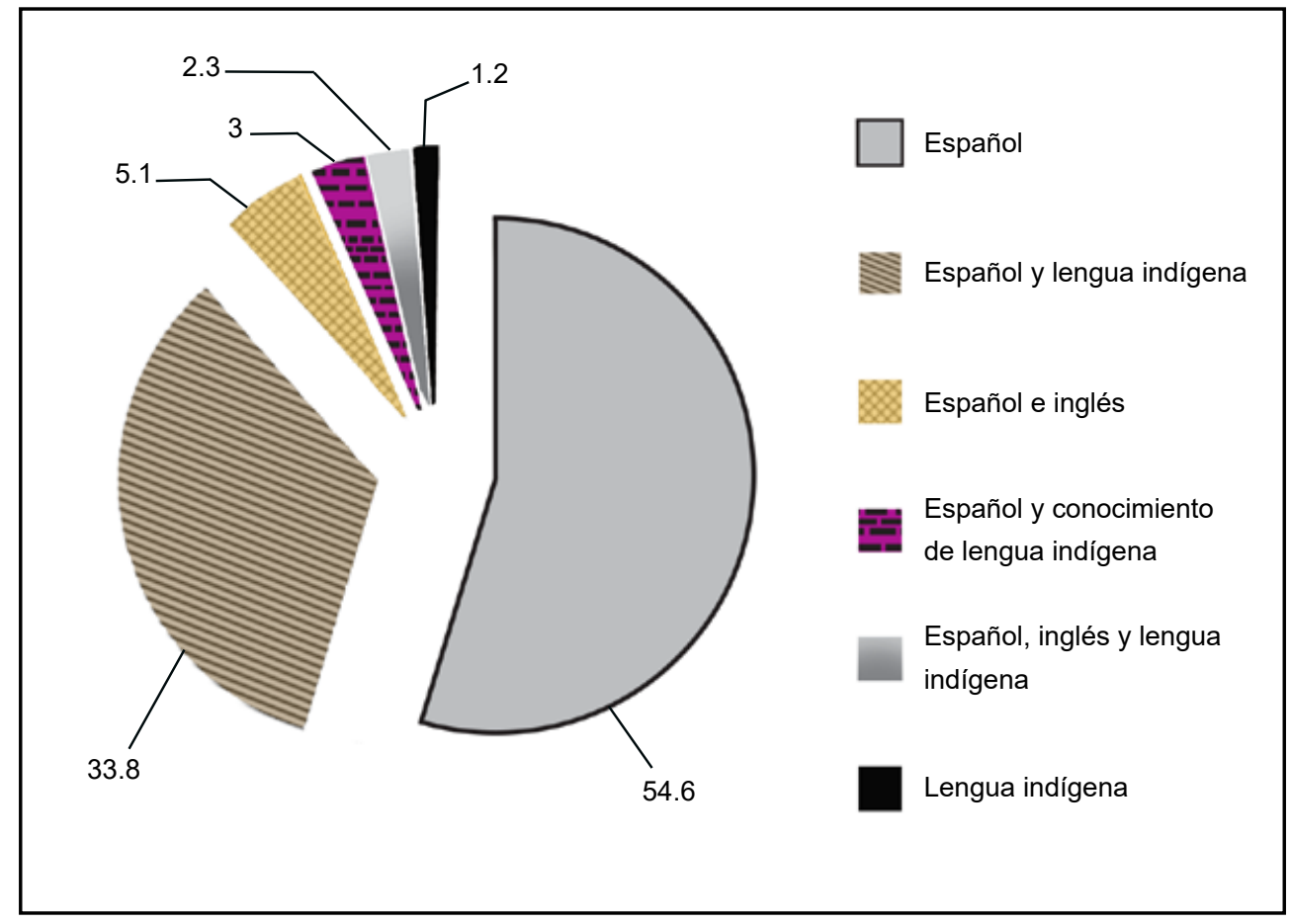

Fuente: Elaboración propia con la base de datos del Cuestionario a Niños, Diagnóstico y evaluación de las estrategias escolares para la interculturalidad: Experiencias locales ante la diversidad cultural de Baja California, El Colegio de la Frontera Norte, 2014.

Además, es posible observar una modalidad de hablantes de español que declara tener conocimiento de una lengua indígena aunque no la dominen (3\%). Según los resultados de los grupos focales, este grupo de niños que afirma tener conocimiento de una lengua indígena puede ser de origen indígena o no, y lo poco que saben lo han aprendido en la escuela a través de los programas de lengua indígena y de la interacción con niños hablantes de lenguas indígenas. 
Las lenguas indígenas que hablan las niñas y los niños son, principalmente: mixteco, triqui, zapoteco, náhuatl y purépecha (ver Figura 4).

Figura 4. Lenguas indígenas que hablan los niños(as) de las escuelas de educación indígena en Baja California (porcentajes)

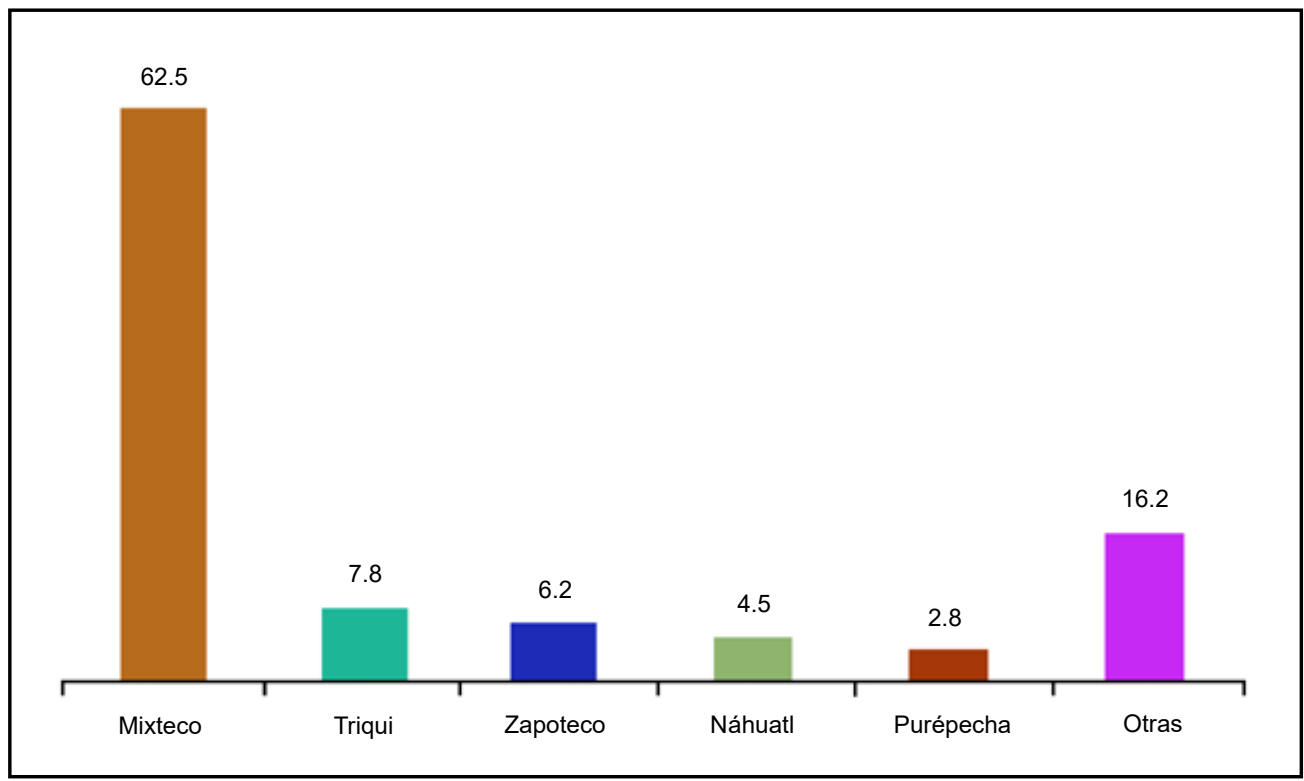

Fuente: Elaboración propia con la base de datos del Cuestionario a Niños, Diagnóstico y evaluación de las estrategias escolares para la interculturalidad: Experiencias locales ante la diversidad cultural de Baja California, El Colegio de la Frontera Norte, 2014.

En correspondencia, los padres de familia hablan las mismas lenguas y en proporción similar a los niños. Más de la mitad de estos padres de familia, al igual que los niños, habla mixteco. Esta información cobra sentido a la luz de los datos presentados antes sobre lugar de nacimiento, en tanto que, poco más de la tercera parte de los padres de familia nació en Oaxaca y, en menor proporción en Guerrero. Ambos estados son sede histórica del pueblo mixteco. Asimismo, los hablantes de triqui y zapoteco tienen como origen el estado de Oaxaca. Los padres de familia hablante de náhuatl y purépecha son originarios de los estados de Veracruz y Michoacán, respectivamente. Por otra parte, se encuentra que menos de $1 \%$ es hablante de una lengua de los pueblos indígenas nativos. El sistema de educación indígena registra 70 escuelas donde asisten alumnos de origen indígena, de las cuales solo 2 tienen presencia de indígenas nativos de herencia aridoamericana: cucapá, kumiai y pai-pai. Llama la atención que de la lengua pai-pai no haya niños o niñas que la hablen o tengan algún conocimiento.

En los grupos focales de escuelas donde hay población indígena nativa, cucapá, en Mexicali, se encontró que ninguno de los niños de la escuela hablaba el idioma. Algunos mencionan que sus padres conocen algunas palabras que les enseñan, y algunos cantos, pero no lo hablan. Varios niños comentaron que sus abuelos son quienes conocen la lengua cucapá. Una niña dice que su abuela sabe hablar tres idiomas "cucapá, lengua indígena e inglés": "Mi Tata, que en paz descanse, a mí y a mi hermano nos enseñaba palabrillas en indio" (Josué, 2014). 
La huella de la migración internacional y los cruces de frontera se encuentran en los hablantes del inglés. Se encontró que algunos padres de familia y niños(as) hablan inglés además del español y, en menor proporción, lo hablan con lengua indígena. En general son los padres quienes proporcionalmente hablan más el inglés en relación con las madres y los niños. Una explicación posible ante estos datos se asocia con el fenómeno del empleo transfronterizo, tal como se documenta para el caso de Tijuana en el trabajo de Corona y Serrano (2010) donde la población indígena en Tijuana posee un patrón commuter similar al de los demás municipios fronterizos de Baja California. De igual forma, en la experiencia de trabajo de campo con los grupos focales, encontramos que los niños expresaron que sus papás y algunos otros familiares (tíos, principalmente) trabajan o han trabajado en Estados Unidos, o bien regresaron deportados de Estados Unidos. Esta situación se relaciona con la movilidad transnacional que se vive en los hogares indígenas asentados en la frontera, con fuertes redes en ambos lados. Por ejemplo se sabe que en Tijuana "los hogares indígenas tienden más a la migración, reciben más inmigrantes y envían más emigrantes hacia Estados Unidos que los hogares no indígenas" (Corona y Serrano, 2010, p. 53). Además, en los grupos focales, encontramos niños y niñas que comentan haber aprendido a hablar inglés con sus papás, sus tíos y sus primos que viven o han vivido en Estados Unidos o bien haber nacido o crecido en Estados Unidos pero al ser deportados alguno de sus padres, han tenido que instalarse en alguna ciudad fronteriza.

\section{Gusto y práctica de la lengua indígena}

La relación entre el gusto y la práctica de una lengua indígena está enmarcada en los procesos de etnización del nacionalismo mexicano con su sistema de jerarquización categorial. Como lo demostró Bourdieu (1984) el gusto está delineado por relaciones sociales de estatus y poder, pero además en este caso de estudio las lenguas indígenas han perdido función comunicativa al ser cada vez más reducido su uso al espacio privado o íntimo. Los niños que hablan lengua indígena en alguna modalidad, ya sean bilingües, trilingües o que solo cuentan con conocimiento de la lengua a partir de lo que han aprendido en el salón de clases o con su familia, manifiestan que sí les gusta hablar la lengua indígena pero en ciertos espacios. Por ejemplo en la escuela Francisco González Bocanegra, del Valle de San Quintín. En el grupo focal con niños fue posible escuchar testimonios como el siguiente:

A mí me gusta la lengua indígena porque nos reconoce como zapotecos y porque es muy divertida la clase porque la profe nos pone a hacer cosas, y a investigar qué significa eso y me sé varias cosas en zapoteco (Suriel, 2014).

Sin complicaciones dicen algunas palabras, ninguno se ríe de su compañero sino que le recuerdan algunas palabras para ayudarle (Juan, 2014).

Los datos cualitativos encuentran eco en los datos cuantitativos, como se observa en la Figura 5 un poco más de la mitad de estos niños afirma que les gusta hablar en lengua indígena con sus familiares $(52 \%)$; mientras que solo a una tercera parte les gusta hablarlo con sus amigos $(30 \%)$ y menos de una quinta parte con los profesores. Definida por el gusto, la lengua indígena sigue siendo una práctica cultural que se recrea principalmente en la vida íntima y sobresale que siendo una escuela intercultural 
no les guste hablar con los profesores. Este dato puede ser analizado por la relación de autoridad que media entre alumno-profesor, el cual inhibe la práctica de la lengua, a la vez que plantea la complejidad de la realización de la interculturalidad en el salón de clase.

Figura 5. Personas con quienes les gusta hablar en lengua indígena (porcentajes)

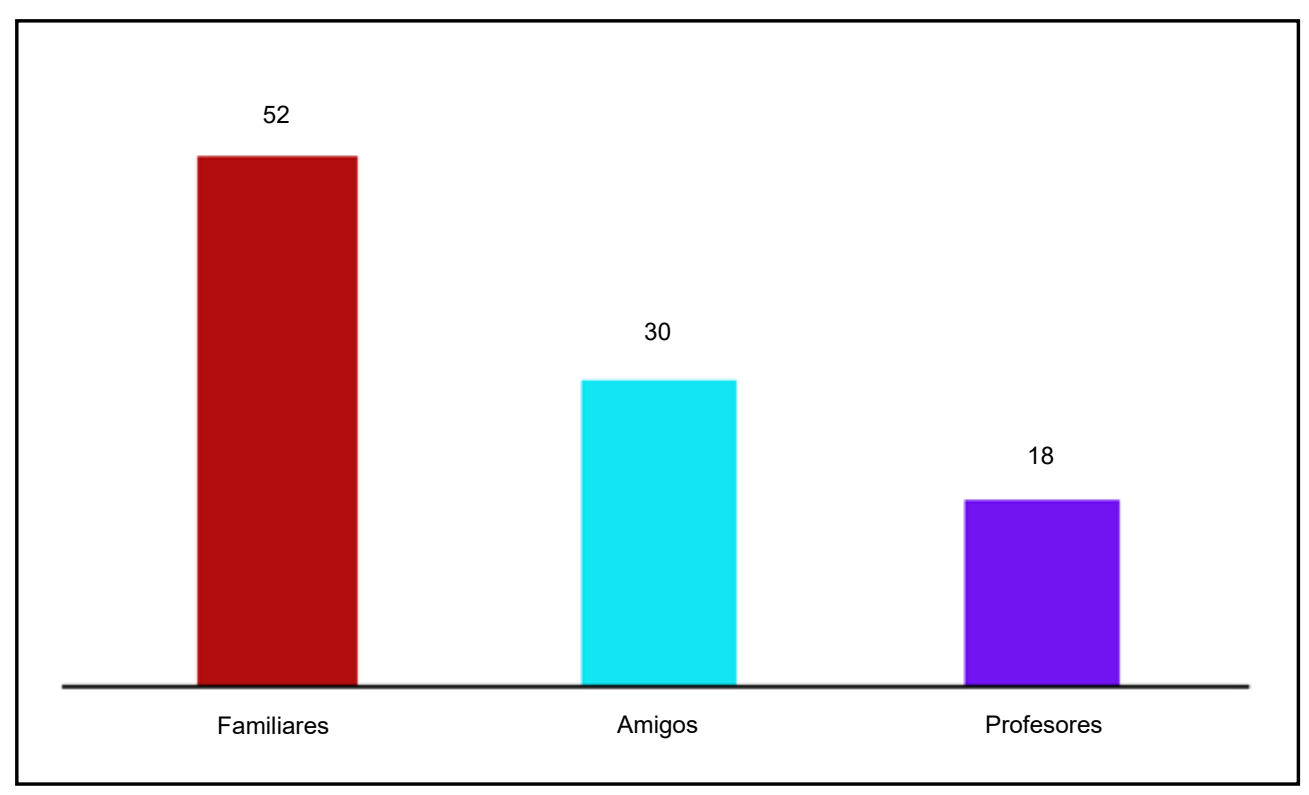

Fuente: Elaboración propia con la base de datos del Cuestionario a Niños, Diagnóstico y evaluación de las estrategias escolares para la interculturalidad: Experiencias locales ante la diversidad cultural de Baja California, El Colegio de la Frontera Norte, 2014.

Aquí tenemos algunas posibles explicaciones que provienen del trabajo de campo con la observación y de los grupos focales. La primera es que en condiciones de migración los niños frecuentemente quedan a cargo de los abuelos por lo que aprenden el idioma de ellos, aun cuando sus padres ya no lo practican. Y la segunda, que la escuela intercultural refuerza el aprendizaje en el aula, a través de su estimulación y porque ahí hay otros niños que lo hablan y con quien pueden practicarlo. Además, en los grupos focales encontramos niños y niñas cuya lengua materna no es la lengua indígena y sin embargo tienen algún conocimiento de ella: frases cortas, canciones, palabras y manifestaron un gusto por aprender más. Llama la atención casos de niños y niñas que no son de origen indígena en términos familiares, pero que manifestaron mucho entusiasmo por hablarlo y por adscribirse como indígenas. Pareciera que a ciertas edades y en contextos de estimulación a la diversidad cultural aún no han construido el prejuicio étnico hacia lo indígena presente en la sociedad de referencia, o bien, están aprendiendo el valor ambivalente de las identificaciones étnicas que llevan a la posible negación identitaria, como lo muestra el pasaje siguiente:

Es mejor hablar muchas lenguas a que solamente se conozca una $[\ldots]$ porque si vas a otros lugares vas a poder platicar con gente que habla diferente lengua a la que tu hables $[y][\ldots]$ porque si vamos a la ciudad de Oaxaca puedes platicar con vecinos y así podemos comunicarnos con otras personas (Pedro, 2014). 


\section{Discriminación e inferiorización cultural}

Como lo señalan Brubaker y Cooper (2001) la comprensión de los procesos identitarios llama a considerar las fuerzas externas que influyen en la categorización e identificación tales como la discriminación étnica institucionalizada y la inferiorización cultural. Como lo asentó Bonfil (1989), el nacionalismo mexicano se ha fundado sobre la desvalorización del indígena presente y la magnificación del pasado indígena. En esa misión, la escuela ha tenido un papel estratégico, en la medida que ha sido uno de los principales vehículos de socialización de las nuevas generaciones. La castellanización se asentó sobre la tarea de mestizar culturalmente a los pueblos indígenas, negando sus lenguas y sus identidades para acercarse a la cultura occidental (Villoro, 1996). Según Martínez (2015, p. 113) existe una tensión clara entre el proyecto estatal de un indigenismo intercultural bilingüe y la estructura de desigualdad que somete a los indígenas a los estratos más bajos y a lo que puede llamarse como estructura de desigualdad étnica. Para Dietz et al. (2008) la educación indígena se ha vuelto un campo de lucha donde convergen las instituciones y los propios movimientos indígenas. A nuestro parecer, esta arena de lucha puede ser observada desde el interior de la escuela en la discriminación que viven los actores escolares, principalmente los niños y los profesores. Para analizar este aspecto se recurre a resultados de los grupos focales. Dos hallazgos generales organizan este análisis: el primero fue la divergencia de percepciones entre profesores y alumnos sobre el tema de la discriminación en el interior de la escuela. Si bien los profesores reconocen la discriminación hacia los indígenas, que ellos mismos viven por su origen indígena, según expresaron, lo ubican más fuera de la escuela. En tanto que los alumnos y alumnas hablan de la discriminación en el salón de clase y el espacio escolar, y además fuera de la escuela. El segundo hallazgo fue que la discriminación tiene su contraparte de resistencia o búsqueda por reconocer como positiva la diferencia, tal vez como un mecanismo de autoafirmación.

En el análisis tomamos las discusiones de los grupos focales con los niños y niñas y solo complementariamente la de los profesores. Las discusiones se organizan en una serie de ejes temáticos lo que llamaremos emblemas o marcas sobre las que se construye la discriminación: la lengua, el color de piel, el lugar origen o procedencia, vestimenta y atributos físicos o corporales. A la vez iremos rastreando los mecanismos de la discriminación y de construcción de la diferencia cultural y jerarquía social que definen a la comunidad escolar.

- La lengua indígena fue el elemento cultural que tuvo más referencias a la discriminación, aun cuando no hay una clase específicamente de lengua indígena, y además la escuela misma tiene una orientación de interculturalidad donde lo indígena está en el centro de muchas actividades escolares. Como se describió al inicio de este ensayo, el porcentaje de niños que hablan lengua indígena es bajo, así que son pocos los niños que hablan lengua indígena $(0.9 \%)$, con diferencias importantes entre los municipios que van de $0.3 \%$ en Mexicali a 3.6\% en Ensenada, donde hay una población inmigrante importante de origen indígena dedicada al trabajo agrícola de exportación. La mayoría tiene el español como su lengua materna, por lo que no "viven" directamente la discriminación por el uso de la lengua indígena y ello lleva a que tomen distancia en sus reflexiones sobre el futuro de la lengua como algo deseable. En tanto los niños que sí la hablan son más reacios a hablar sobre 
el asunto, son los que agachan la cabeza cuando pedimos opiniones sobre si les gusta hablar la lengua o no. Los niños hablantes hacían referencia a la vergüenza que sentían de hablarlo frente a sus compañeros de clase o en el recreo. Hablaban de las burlas o insultos ante un español limitado o bien sus diálogos en lengua indígena. En los grupos de discusión les pedíamos que si nos podían decir alguna frase en lengua indígena y no siempre fue posible lograrlo, aún con los niños que eran muy participativos en español.

En la ciudad de Tijuana fue posible escuchar la valoración de la lengua indígena en competencia con otras lenguas como el inglés: en la escuela El Pípila, durante el grupo focal y en medio de la discusión sobre la valoración de la lengua indígena, una niña compartió:

Yo escuché a un señor que le estaba diciendo a su hijo que por qué les estaban enseñando el mixteco, si el inglés —como por si ellos sacan papeles- se pueden ir a trabajar a Estados Unidos. Pero dice que no, que el mixteco no puede servir para nada (Abigail, 2014).

En esta discusión el grupo coincidió en apuntar que hablar inglés es importante porque "allá" (Estados Unidos) hay mucho trabajo. De hecho, en palabras de Pedro (2014) saber hablar inglés ayuda a "tener un buen puesto de trabajo" mientras que hablar mixteco es "para comunicarnos con las personas que no saben hablar español”.

La alusión a la pena y la vergüenza señala el mecanismo de la inferiorización que funciona en relaciones de dominación donde ciertos atributos están cargados de valores negativos. Esta situación es consistente con el estudio de Martínez y Rojas (2006) sobre niños otomíes, mixtecos y purépechas en escuelas urbanas de Guadalajara donde identifican que, de manera general, estos niños solo hablan español con excepción de la hora del recreo. En el patio de la escuela se presenta una segregación por grupos de niños a partir de la condición étnica indígena y de género donde "etiquetas como huicholito y oaxaco son frecuentes en el contexto de la interacción entre estudiantes - y con algunos profesores- como formas de identificación del alumnado indígena” (Martínez y Rojas, 2006, p. 82). A partir de estas etiquetas, los niños indígenas se distinguen de los niños no indígenas (o mestizos).

Pero a la vez, la reflexión sobre la lengua indígena entre los niños desató comentarios sobre la importancia de conservar la lengua como parte de la tradición y costumbre que no debería perderse porque se asocia con los ancestros. Incluso, fue una constante que los niños dijeran que sí querían enseñar a sus hijos su lengua indígena, aunque ellos ya no la hablen. ¿De dónde viene este deseo de reproducción lingüística de una lengua que no hablan? Tenemos dos posibles explicaciones, están respondiendo a las expectativas de sus profesores a que actúen de esta forma o bien que una vez perdido ese elemento cultural su valor se trastoca en positivo. La discriminación hacia la lengua surgió con más claridad entre los profesores y los padres de familia en los grupos focales y en las entrevistas.

Profesores de la escuela Álvaro Obregón, en el Valle de San Quintín, manifestaron que "algunos padres de familia mantienen la idea de ver como negativo el utilizar las lenguas indígena porque [...] algunos papás [...] muy pocos $[\ldots]$ tienen la idea de que si hablo una lengua indígena te castigan" 
(Hernández, 2014). La violencia de la discriminación puede ser extrema como la vivida por uno de los profesores, quien menciona que tuvo que enfrentarse a golpes para parar las agresiones por hablar lengua indígena. Esa violencia fue tan fuerte, que su madre decidió no enseñarles más el mixteco y dejar de hablarlo con ellos (López, 2015).

- El color de piel, ser moreno fue una referencia de discriminación. La alusión constante al color de la piel refiere el proceso de racialización como hegemonía global, con su expresión nacional y local. El color de piel es reforzado por atributos físicos como la estatura o la complexión corporal, convirtiéndose en un "marcador de diferencias (culturales) pensado como 'natural', ya que se presenta 'evidente'; y así se sientan las bases del racismo biológico" (Aguilar, 2012, p. 74). En los grupos focales del alumnado hubo alusiones tales como que la piel oscura "tiene gérmenes", "es como ser indio". Con el color de la piel surgió con mayor claridad y en forma explícita el adjetivo "oaxaco" como insulto, pero a la vez como categoría identitaria inferior. La categoría "oaxaco" sustituye a la de indígena por lo que se puede aplicar a los niños de origen purépecha, mixteco o náhuatl, porque condensa la inferiorización asociada a lo indígena. La vitalidad de la categoría oaxaco se expande por toda la región noroeste de México, y es producto de la migración jornalera del sur del país a los campos agrícolas que producen para la exportación a Estados Unidos. Tal categoría que interseca la condición étnica y la posición de clase social fue acuñada en el encuentro de los inmigrantes de origen indígena en los campos agrícolas y la población nativa del norte de México y se ha difundido hacia las zonas urbanas (Velasco y Hernández, 2018).

En los grupos focales, los niños consideraron que las personas de diferente color de piel valen lo mismo por sus derechos y no deben ser discriminados: "Valen igual, porque son humanos y todos tienen derecho. No importa lo de afuera sino lo de adentro [...] tienen los mismos derechos y los mismos sentimientos" (Suriel, 2014), "no debemos de discriminarlos por el color, porque todos tenemos derechos y somos seres humanos" (Jorge, 2014). Sin embargo identifican que sí existe un trato distinto por el color de piel, fuera y dentro de la escuela. Para explicar este punto, los niños recuerdan un caso en particular: "Un niño que va en la secundaria en 1ro se burla de uno que es de Oaxaca. Le dice 'Pinchi morro negro oaxaco'. Y le digo 'No te burles, tú también estás moreno y nadie se burla de ti' (Suriel, 2014)". "En mi casa como va conmigo se burla de él y le dicen oaxaco", refuerza Jorge (2014). "A mí una vez me dijeron así. Se burlaban porque era de Oaxaca. Me dijeron 'oaxaco'. Lo dicen como grosería porque dicen que los de Oaxaca son negros, pobres y hablan otra lengua", comenta un niño. "Y siempre, cada día discriminan aquí en la Candelaria. No hay ni una vez en que dejen de discriminar. Aquí pasa también en el recreo, en los salones, que nos dicen 'tú, quítate negro' o a veces porque están gordos 'tú, quítate gordo'” (grupo focal, 2014). Comparten que hay un niño que tiene su oreja corta porque está enfermo y también se burlan de él: "otro niño le dice 'Pinchi oreja mocha'. Y yo le digo 'no te burles o le digo al director"' (grupo focal, 2014).

En el grupo focal en la ciudad de Tijuana, también el color de la piel ocupó la discusión entre los niños en forma más abierta que la lengua indígena. En general los niños establecieron una polémica sobre si las personas de piel blanca son más frágiles que las personas de piel oscura. Sus participaciones se 
dirigieron hacia el color moreno de piel. Por ejemplo, Abigail (2014) cuenta el caso de una niña que era "más morenita" que ella a quien le hacían burla por esa razón y le decían que tenía gérmenes y Gustavo Sánchez (2014), uno de los participantes del grupo focal, quien comentó que uno de sus compañeros del grupo lo discriminaba porque le decía "oaxaco". A partir del último comentario, algunos niños afirmaron que les han dicho "oaxaco" y que esta expresión los hace sentir mal porque "nos discriminan". Sin embargo, uno de los niños expresó: "No me siento mal porque es lo mismo, ellos también. Todos vinimos de lo mismo" (Pedro, 2014), "sus abuelos y sus antepasados también vinieron de ahî", remata Gustavo (Sánchez, 2014). En estos últimos comentarios sugieren que el color de piel se conecta con el lugar de procedencia, de Oaxaca y de la ascendencia.

- Origen histórico-geográfico, como lugar de nacimiento y de descendencia. El concepto de ancestralidad refiere al vínculo de la persona con sus antepasados y la dinámica de identificación con los pueblos o con la historia familiar. Los niños y niñas reconocían los lugares de origen o procedencia de sus padres y la diferencia entre ellos al respecto, aunque la mayoría de ellos son ya nacidos en Baja California, a través de las historias familiares o la comida. Esta diferencia no siempre estaba asociada a la inferiorización sino solo a ser diferentes. Sin embargo para los niños que procedían de Oaxaca o Guerrero esa diferencia tomaba un matiz negativo, porque se engarzaba en la intersección con su color y de nuevo la lengua indígena de sus padres o ancestros y de nuevo con la categoría de "oaxaco" ya ilustrada en el pasaje anterior de la voz de los niños y niñas.

- Vestimenta, en alusión al origen étnico y la clase social. Los niños y niñas hacen alusión a estar mejor vestidos o la vestimenta de los padres o madres (sobre todo con respecto a las madres triquis que usan el huipil rojo). Es difícil hablar de clase social dado la condición homogénea en términos económicos de las familias de los niños de las escuelas indígenas, pero sí puede haber diferencias de estratos o de recursos familiares que los niños y niñas perciben a través de su vestimenta. Son las microdesigualdades que producen las estructuras de discriminación social regional y nacional.

- El rendimiento escolar es una fuente de diferencia y jerarquía en el mundo escolar, y fuente de malestar entre los niños(as). Los niños aplicados frente aquellos con bajos rendimientos. Los niños con habilidades sociales como hablar en público frente aquellos que son tímidos y no se atreven a dar su opinión.

La burla a través de frases de ridiculización de la persona por sus atributos fue el recurso más mencionado tanto en el espacio escolar del aula como en los juegos durante los recreos escolares. Generalmente la burla precede a la violencia física entre los niños, según sus propios relatos. La construcción de la categoría cultural "oaxaco" interseca un conjunto de líneas de discriminación en torno a la lengua indígena, el color de piel, características físicas, el lugar de procedencia familiar o ancestral. En tanto que otras categorías propias de la vida escolar se organizan en torno a los atributos físicos corporales y del rendimiento escolar que infligen sufrimiento en los niños, minusvalía. En todas las categorías el mecanismo de construcción de la diferencia deteriorada es la inferiorización a través de la burla principalmente, además del insulto o la violencia física. 
¿Qué piensan los profesores respecto de la discriminación y la categoría "oaxaco" en el espacio escolar? En el grupo focal se lanzó esta pregunta y los profesores guardaron silencio por un par de minutos, para agregar que sí han escuchado el término pero fuera de la escuela. Incluso, hubo una opinión que era una forma de referirse al origen oaxaqueño, no siempre insultante. Estas reflexiones, contrastaron con las opiniones de los niños y niñas, a la vez con las reflexiones de los propios maestros en entrevistas posteriores.

En entrevistas en profundidad por separado, algunos profesores y profesoras mencionaron la discriminación que habían vivido por hablar lengua indígena y la negación de sus padres a enseñárselas bajo el argumento de la discriminación. Uno de los profesores relató el acoso escolar que vivió por hablar lengua indígena en la escuela en Baja California Sur, donde sus padres habían migrado. La única forma de evitarlo fue enfrentando a golpes a los acosadores. Esa discriminación y violencia vivida lo llevó a decidir ser profesor en escuela indígena para "ayudar a los niños a no sentirse menos por su origen o por su lengua indígena" (López, 2015). Esta discrepancia de percepciones sobre la vigencia de la discriminación en el espacio escolar entre profesores y alumnado es posible que responda a que las dinámicas escolares de ambos sectores se dan en mundos fragmentados. Además, la visión optimista de los profesores y profesoras al respecto puede responder a una manera de manejar la dificultad para responder a ese reto. En general los profesores y profesoras perciben que con el programa multilingüe ha disminuido la discriminación al interior de la escuela. Por ejemplo, mencionan que al inicio del programa, los niños negaban que sus padres hablaran lengua indígena (Sarmiento, 2014). De alguna forma los profesores están tratando de reconstruir el sentido de la diferencia eliminando su carga negativa y promoviendo la pertenencia positiva, mientras los niños viven el horizonte de la discriminación étnica y de clase, filtrando sus experiencias escolares con su vida en la colonia y en el espacio familiar.

\section{Reflexiones finales}

Un comentario recurrente de los profesores del sistema de educación indígena en Baja California fue el supuesto equivocado del modelo intercultural mexicano que en primera instancia está dirigido solo a lo indígena y segundo, pero consecuentemente, sobre la lengua indígena como la lengua materna del alumnado. Esta crítica docente, es consistente con los datos aquí presentados. Hay una diversidad cultural en el alumnado que señala una heterogeneidad de orígenes histórico-regionales y lingüísticos con el dominio del español como lengua materna, al ser sumamente baja la presencia de niños monolingües de lengua indígena. Esta diversidad cultural está relacionada con la migración interna de sur a norte, pero también internacional, vía los flujos de migración regional hacia Estados Unidos y los más recientes flujos de retorno y deportación de ese país.

Esta diversidad cultural no implica en sí mismo un diálogo cultural, requiere de acción institucional y particularmente de estrategias docentes de aplicación pragmática del modelo de interculturalidad, asunto que no desarrollamos en este texto. Lo que sí se observó fueron los obstáculos a la interculturalidad y que provienen de la discriminación étnica emergente en los salones de clase y de la que ellos no son ajenos, 
ya que comparten la condición de clase y étnica de origen con el alumnado. Si bien, esta condición supone empatía cultural dada la experiencia histórica común, lo cierto es que también significa un reto de alejamiento de su propia condición de clase y étnica, para reconocer las dinámicas de discriminación en el salón de clase. El artículo presenta un conjunto de elementos culturales que son objeto de desvalorización muy específica y que en conjunto articulan la discriminación étnica y de clase en las escuelas bajo estudio.

La primera es la lengua indígena como objeto de discriminación étnica al asociarse con inferioridad adscriptiva para los hablantes. La segunda es el color y otras características físicas, como racialización de la inferioridad. Y la tercera es el lugar de origen, como origen ancestral, que vincula a la persona a un colectivo de estatus social y cultural diferenciado y subordinado históricamente. Estos tres elementos pueden encontrar una síntesis en la categoría "oaxaco" que condensa la indigeneidad y agrega una condición de clase social y de extranjero, por el peso del trabajo agrícola como una ocupación frecuente entre las familias inmigrantes. Existe una dimensión emocional de la discriminación que refiere estados de vergüenza por hablar la lengua, tener la piel morena y provenir de familias cuyo origen histórico son regiones etnizadas como Oaxaca, Guerrero o Puebla, por ejemplo.

La escuela indígena diversa, a raíz de las migraciones, funciona con diferencias culturales que a su interior fragmenta la comunidad escolar y la cual requiere de un modelo intercultural que asuma esas nuevas líneas de discriminación social y cultural.

\section{Referencias}

Aguilar, J. (2012). Diferencia racial en docentes de educación básica de Tijuana y Tecate. Un estudio exploratorio. Culturales, VIII(15), 47-80.

Barabas, A. M. (2000). La construcción del indio como bárbaro: De la etnografía al indigenismo, Alteridades, 10(19), 9-20.

Bertely, M. (2006). Historias, saberes indígenas y nuevas etnicidades en la escuela. México: Centro de Investigación y Estudios Superiores en Antropología Social.

Bertely, M., Gasché, J. y Podestá, R. (Coords.). (2008). Educando en la diversidad Cultural. Investigaciones y experiencias educativas interculturales y bilingües. Quito, Ecuador: Abya Yala, Centro de Investigación y Estudios Superiores en Antropología Social, Universidad Pedagógica Nacional, Instituto de Ciencias Sociales y Humanidades-Benemérita Universidad Autónoma de Puebla.

Bonfil, G. (1989). México profundo: Una civilización negada. México: Grijalbo.

Bourdieu, P. (1984). La distinción: una crítica social del juicio del gusto. París, Francia: Minuit.

Brubaker, R. y Cooper, F. (2001). Más allá de "Identidad". Apuntes de Investigación del CECYP, (7).

Castro, G. (2002). La formación de los educadores que atienden a las niñas y niños migrantes en el noroeste de México: Una preocupación actual. En F. Soberanes, I. Seda y J. Viveros (Eds.), Primer Congreso Nacional de Educación Indigena e Intercultural. Memorias (pp. 261-265). México: Educación Indígena e Intercultural, Unidad de Capacitación e Investigación Educativa para la Participación. 
Cedillo, S., García, H., Márquez, A., Pérez, E., Reyes, S. y Sachezllanes, P. (2002). Educación intercultural: Una propuesta para la población infantil migrante. En Foro Invisibilidad y conciencia: Migración interna de niñas y niños jornaleros agrícolas en México. Recuperado de http://www.uam.mx/cdi/pdf/eventos/invisibilidad/ conafe.pdf

Coordinación General de Educación Intercultural y Bilingüe (CGEIB). (2004). Políticas y fundamentos de la educación intercultural bilingüe en México. México: Secretaría de Educación Pública.

Corona, R. y Serrano, A. (2010). Cuantificación y perfil sociodemográfico de los hogares en condición indígena en el municipio de Tijuana. En L. Velasco (Coord.), Tijuana indígena. Estudio sobre las condiciones de vida e integración social de la población indígena a la ciudad (pp. 23-53). México: Comisión Nacional para el Desarrollo de los Pueblos Indígenas.

Corona, S. y Barriga, R. (2004). Introducción. En S. Corona y R. Barriga (Coords.), Educación indígena en torno a la interculturalidad (pp. 9-18). México: Universidad de Guadalajara, Universidad Autónoma Metropolitana, Petra.

Coubès, M., Vela. R. y Velasco, L. (2010). Integración espacial y sociocultural de la población indígena a la vida urbana. En L. Velasco (Coord.). Tijuana indígena: Estudio sobre las condiciones de vida e integración social de la población indígena a la ciudad (pp. 57-90). México: Comisión Nacional para el Desarrollo de los Pueblos Indígenas.

Czarny, G. (2008). Pasar por la escuela: Indígenas y procesos de escolaridad en la ciudad de México. México: Universidad Pedagógica Nacional.

Díaz-Polanco, H. (1978). Indigenismo, populismo y marxismo. Nueva Antropología, III (9), 7-32.

Dietz, G. y Mateos, S. (2013). Interculturalidad y educación intercultural en México: Un análisis de los discursos nacionales e internacionales en su impacto en los modelos educativos mexicanos. México: Secretaría de Educación Pública, Coordinación General de Educación Intercultural y Bilingüe.

Dietz, G., Mendoza, G. y Téllez, S. (2008). Introducción. En G. Dietz, G. Mendoza y S. Téllez (Eds.), Multiculturalismo, educación intercultural y derechos indígenas en las Américas (pp. 7-19). Quito, Ecuador: Ediciones Abya-Yala.

Durin, S. (2007). ¿Una educación indígena intercultural para la ciudad? El Departamento de Educación Indígena en Nuevo León. Frontera Norte, 19(38), 63-90.

Garduño, E. (2003). Los indígenas en el norte de México: Ícono de una era transnacional. En J. M. Valenzuela (Coord.), Por las fronteras del norte. Una aproximación cultural a la frontera México-Estados Unidos (pp. 130-168). México: Fondo de Cultura Económica.

Grimson, A. (2011). Los límites de la cultura. Crítica de las teorías de la identidad. Buenos Aires, Argentina: Siglo XxI.

Instituto Nacional de Estadística y Geografía (Inegi). (2010). Principales resultados por localidad (ITER). Recuperado de https://www.inegi.org.mx/programas/ ccpv/2010/

Lestage, F. y Pérez, T. (2000). Una escuela bilingüe ¿Para quién? El caso de los migrantes indígenas en Tijuana, B.C. Ponencia presentada en el seminario Dinámicas de la población indígena en México: Problemáticas contemporáneas, México, Distrito Federal. 
López-Bonilla, G. y Tinajero, G. (2011). Los maestros indígenas ante la diversidad étnica y lingüística en contextos de migración. Cuadernos Comillas, (1), 5-21.

Martínez, E. (2015). La educación intercultural y bilingüe (ЕIB) en México. ¿El camino hacia la construcción de una ciudadanía democrática? Relaciones. Estudios de Historia y Sociedad, xxхVI(141), 103-131.

Martínez, R. y Rojas, A. (2006). Indígenas urbanos en Guadalajara: Etnicidad y escuela en niños y jóvenes otomíes, mixtecos y purépechas. En P. Yanes, V. Molina y Ó. González (Coords.), El triple desafío. Derechos, instituciones y políticas para la ciudad pluricultural (pp. 69-93). México: Universidad Autónoma de la Ciudad de México, Gobierno del Distrito Federal, Secretaría de Desarrollo Social.

Medina, P. (2007). Configuración de fronteras, interculturalidad y políticas de identidad. Niñ@s indígenas, escuela y migración (México). Tramas, (28), 171-194.

Muñoz, H. (2001). Interpretación de la educación indígena bilingüe en México. En H. Muñoz (Ed.), Un futuro desde la autonomía y la diversidad (pp. 307-337). México: Universidad Veracruzana.

Organización de las Naciones Unidas para la Educación, la Ciencia y la Cultura (Unesco). (2006). Directrices de la UNESCO sobre educación intercultural. Recuperado de http://unesdoc.unesco.org/images/0014/001478/147878s.pdf

Peña, G. de la (2005). Social and Cultural Policies. Toward Indigenous Peoples: Perspectives from Latin America. The Annual Review of Anthropology, (34), 717-739.

Ramírez, J. y Lara, J. (2009). Experiencias innovadoras en educación intercultural. En Segundo Congreso Nacional de Educación Indigena e Intercultural. Memoria (vol. II, pp. 75-82). México: Comité Promotor del Congreso Nacional de Educación Indígena e Intercultural, Unidad de Capacitación e Investigación Educativa para la Participación, A. C. Recuperado de https://www.scribd.com/document/180677616/Vol-2

Saldívar, E. (2006). Estrategias de atención a la diferencia étnica en escuelas primarias del D.F. En P. Yanes, V. Molina y Ó. González (Coords.), El triple desafio. Derechos, instituciones y políticas para la ciudad pluricultural (pp. 99-123). México: Universidad Autónoma de la Ciudad de México, Gobierno del Distrito Federal, Secretaría de Desarrollo Social.

Sandoval, F. (2004). Interculturalidad, una mirada desde abajo. Las relaciones interculturales de una comunidad indígena de Oaxaca, México. En S. Corona y R. Barriga (Coords.), Educación indígena en torno a la interculturalidad (57-65). México: Universidad de Guadalajara, Municipio de Zapopan, Universidad Autónoma Metropolitana-Xochimilco.

Schmelkes, S. (2004). La educación intercultural: un campo en proceso de consolidación. Revista Mexicana de Investigación Educativa, 9(20), 9-13.

Sistema Educativo Estatal (SEE). (2012). Principales cifras estadísticas 2011-2012. Recuperado de http://www.educacionbc.edu.mx/publicaciones/estadisticas/2012/ index_files/slide0001.htm

Stavenhagen, R. (2006). La presión desde abajo: Derechos humanos y multiculturalismo. En D. Gutiérrez (Coord.), Multiculturalismo. Desafios y perspectivas (pp. 213-240). México: Universidad Nacional Autónoma de México, El Colegio de México, Siglo XXI. 
Velasco, L. (2010). Población indígena, migración e integración social a la ciudad de Tijuana. En L. Velasco (Coord.), Tijuana indigena: Estudio sobre las condiciones de vida e integración social de la población indígena a la ciudad (pp. 7-22). México: Comisión Nacional para el Desarrollo de los Pueblos Indígenas.

Velasco, L. y Coubès, M. (2006). Atención educativa intercultural a toda la infancia en migración interna: estudio de caso de Baja California. Manuscrito. Reporte de Investigación. México: El Colegio de la Frontera Norte, Fondo de las Naciones Unidas para la Infancia, Sistema Educativo Estatal, Consejo Nacional de Fomento Educativo, Instituto Nacional de Educación para Adultos, Programa de Atención a Jornaleros Agrícolas.

Velasco, L. y Hernández, C. (2018). Migración, trabajo y asentamiento en enclaves globales. Indígenas en Baja California Sur. México: El Colegio de la Frontera Norte, Comisión Nacional para el Desarrollo de los Pueblos Indígenas.

Velasco, L. y Rentería, D. (2015). Diagnóstico sobre la diversidad cultural y las prácticas de discriminación en la comunidad escolar. México: El Colegio de la Frontera Norte, Consejo Nacional de Ciencia y Tecnología, Dirección General de Educación Indígena.

Velasco, L., Zlolniski, C. y Coubès, M. L. (2014). De jornaleros a colonos: Residencia, trabajo e identidad en el Valle de San Quintín. México: El Colegio de la Frontera Norte, Comisión Nacional para el Desarrollo de los Pueblos Indígenas.

Verdery, C. (1994). Ethnicity, Nationalism and State-making. Ethnic Groups and Boundaries: Past and Future. En H. Vermeulen y C. Govers (Eds.), The Anthropology of Ethnicity (pp. 33-58). Ámsterdam, Países Bajos: M. Nijhoff International, Spinhuis.

Villoro, L. (1996). Los grandes momentos del indigenismo en México. México: El Colegio de México, El Colegio Nacional, Fondo de Cultura Económica.

Walsh, C. (2007). Interculturalidad y colonialidad del poder. Un pensamiento y posicionamiento 'otro' desde la diferencia colonial. En S. Castro y R. Grosfoguel (Eds.), El giro decolonial. Reflexiones para una diversidad epistémica más allá del capitalismo global (pp. 47-62). Bogotá, Colombia: Siglo de Hombres Editores.

Wieviorka, M. (2003). Diferencias culturales, racismo y democracia. En D. Mato (Coord.), Políticas de identidades y diferencias sociales en tiempos de globalización (pp. 17-32). Caracas, Venezuela: Universidad Central de Venezuela.

\section{Entrevistas}

Abigail. (3 de abril de 2014). Por Daniela Rentería, Diagnóstico y evaluación de las estrategias escolares para la interculturalidad: Experiencias locales ante la diversidad cultural de Baja California [Grupo focal]. El Colegio de la Frontera Norte, Tijuana, Baja California, México.

Hernández, M. del C. (31 de marzo de 2014). Por Laura Velasco, Diagnóstico y evaluación de las estrategias escolares para la interculturalidad: Experiencias locales ante la diversidad cultural de Baja California [Grupo focal]. El Colegio de la Frontera Norte, Valle de San Quintín, Baja California, México. 
Jorge. (4 de abril de 2014). Por Laura Velasco, Diagnóstico y evaluación de las estrategias escolares para la interculturalidad: Experiencias locales ante la diversidad cultural de Baja California [Grupo focal]. El Colegio de la Frontera Norte, Camalú, Ensenada, Baja California, México.

Josué. (30 de junio de 2014). Por Daniela Rentería, Diagnóstico y evaluación de las estrategias escolares para la interculturalidad: Experiencias locales ante la diversidad cultural de Baja California [Grupo focal]. El Colegio de la Frontera Norte, El Mayor Cucapá, Mexicali, Baja California, México.

Juan. (30 de septiembre de 2014). Por Laura Velasco y Daniela Rentería, Diagnóstico y evaluación de las estrategias escolares para la interculturalidad: Experiencias locales ante la diversidad cultural de Baja California [Grupo focal]. El Colegio de la Frontera Norte, Playas de Rosarito, Baja California, México.

López, A. (Abril de 2015). Por Laura Velasco, Diagnóstico y evaluación de las estrategias escolares para la interculturalidad: Experiencias locales ante la diversidad cultural de Baja California [Grupo focal]. El Colegio de la Frontera Norte, Camalú, Ensenada, Baja California, México.

Pedro. (3 de abril de 2014). Por Daniela Rentería, Diagnóstico y evaluación de las estrategias escolares para la interculturalidad: Experiencias locales ante la diversidad cultural de Baja California [Grupo focal]. El Colegio de la Frontera Norte, Tijuana, Baja California, México.

Sánchez, G. (22 de abril de 2014). Por Laura Velasco, Diagnóstico y evaluación de las estrategias escolares para la interculturalidad: experiencias locales ante la diversidad cultural de Baja California [Grupo focal]. El Colegio de la Frontera Norte, Camalú, Ensenada, Baja California, México.

Santiago, R. (23 de abril de 2014). Por Laura Velasco, Diagnóstico y evaluación de las estrategias escolares para la interculturalidad: Experiencias locales ante la diversidad cultural de Baja California [Grupo focal]. El Colegio de la Frontera Norte, Camalú, Ensenada, Baja California, México.

Sarmiento, Z. (4 de abril de 2014). Por Laura Velasco, Diagnóstico y evaluación de las estrategias escolares para la interculturalidad: Experiencias locales ante la diversidad cultural de Baja California [Grupo focal]. El Colegio de la Frontera Norte, San Quintín, Ensenada, Baja California, México.

Soto, C. (24 de enero 2014). Por Daniela Rentería, Diagnóstico y evaluación de las estrategias escolares para la interculturalidad: Experiencias locales ante la diversidad cultural de Baja California [Grupo focal]. El Colegio de la Frontera Norte, Playas de Rosarito, Baja California, México.

Suriel. (4 de abril de 2014). Por Laura Velasco, Diagnóstico y evaluación de las estrategias escolares para la interculturalidad: Experiencias locales ante la diversidad cultural de Baja California [Grupo focal]. El Colegio de la Frontera Norte, Camalú, Ensenada, Baja California, México. 
Laura Velasco Ortiz

Mexicana. Es doctora en Ciencias Sociales con especialidad en Sociología por El Colegio de México. Profesora-investigadora de El Colegio de la Frontera Norte. Líneas de investigación: migraciones, movilidad y transformaciones identitarias; acción colectiva y políticas de identidad; y fronteras y procesos de clandestinidad. Entre sus principales publicaciones: Cross-border Mobility and Clandestine Practices: Scenarios of Violence in the Mexico-United States Border Region, Human Organization (2016); Métodos cualitativos y su aplicación empirica. Por los caminos de la investigación sobre migración internacional (2012), coordinado con Marina Ariza, El Colef-unAm; Mexican Voices of the Border Region (2011), en coautoría con el Dr. Oscar Contreras, Temple University Press.

\section{Daniela Rentería}

Mexicana. Es doctora en Ciencias Sociales con especialidad en Estudios Regionales. Profesora de la Universidad Iberoamericana, Tijuana, Baja California. Sus líneas de investigación: educación indígena e interculturalidad; agentes y espacios escolares en contextos de diversidad cultural; modelos educativos interculturales en contextos de alta movilidad humana. 